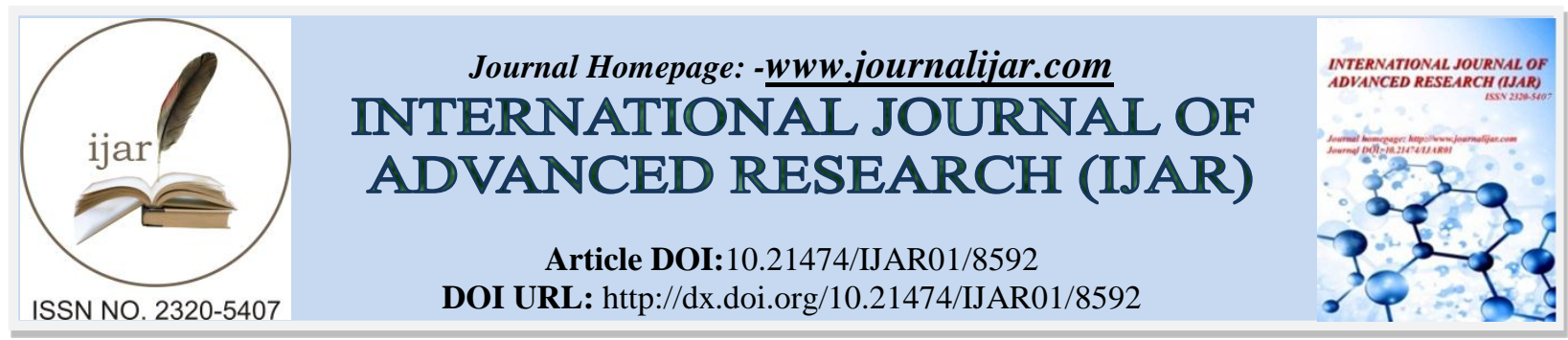

RESEARCH ARTICLE

\title{
TRANSCUTANEOUS ELECTRICAL POSTERIOR TIBIAL NERVE STIMULATION FOR CHRONIC ANAL FISSURE: A PRELIMINARY STUDY.
}

\author{
Hany Salah El Den Tawfik ${ }^{1}$, Emad Mustafa Abd El Hafez ${ }^{1}$, Ahmad Mustafa Nawar ${ }^{2}$ and Mikel Botros Labib. \\ 1. Professor of general surgery faculty of medicine Banha University. \\ 2. Lecturer of general surgery faculty of medicine Banha Universit. \\ 3. Specialist of general and laparoscopic surgery.
}

\section{Manuscript Info}

\section{Manuscript History}

Received: 02 January 2018

Final Accepted: 04 February 2019

Published: March 2019

Key words:-

Chronic anal fissure. Transcutaneous electrical nerve stimulation. Posterior tibial nerve.

\begin{abstract}
Purpose: Recent studies showed that sacral nerve stimulation might be an effective treatment option for chronic anal fissure. We aimed to evaluate the efficacy of transcutaneous electrical nerve stimulation as a noninvasive alternative treatment for chronic anal fissure by stimulating the sacral nerve in the ankle via the posterior tibial nerve.

Method: In this prospective study, transcutaneous electrical nerve stimulation was applied for 20 min every day for 5 days in a week, for a period of 2 weeks in addition to conventional medical treatment in twenty patients. Wexner's constipation score, visual analog scale for pain, symptom relief, compliance, fissure healing, and side effects were evaluated before and after treatment (days $0, \mathbf{1 0}$, and 30).

Results: Twenty patients (fifteen females/five males) with a mean age of $34.75 \pm 11.42$ years were enrolled in the study. The improvement of symptoms after the fifth day of treatment was seen in 5 patients, and mucosal healing was observed in fourteen patients 30 days after the treatment. Wexner's constipation and visual analog scale scores for pain decreased significantly $(\mathrm{p}=0.000$ and $\mathrm{p}=0.000$, respectively).

Two patients underwent surgery at follow-up due to persistence of symptoms, and lateral sphincterotomy was done.

Conclusions: Transcutaneous electrical nerve stimulation application to the posterior tibial nerve has the potential to be an alternative treatment option for chronic anal fissure patients who seek noninvasive treatment modality.
\end{abstract}

Copy Right, IJAR, 2019,. All rights reserved.

\section{Introduction:-}

Chronic anal fissure is one of the most frequent and painful perianal conditions. [1]. Fissures persisting for longer than 4 weeks, or recurrent fissures, are generally defined as chronic [2]. Chronic anal fissure has distinct anatomical features, such as canoe shape tear with visible sphincter fibers at the fissure base, anal papillae, sentinel piles, and indurated margins.

Clinical symptoms are anal pain during or after defecation accompanied by bright red rectal bleeding and pruritus ani. The treatment strategies focus on the spasm of the internal sphincter, which is the most consistent finding 
because the relief of the spasm has been associated with relief of pain and healing of the fissure [3].

Treatment guidelines for chronic anal fissure include nonsurgical management as well as surgical management. [4]. In the treatment of chronic anal fissure, surgical interventions are the most effective therapies. The standard surgical procedure is lateral internal sphincterotomy (LIS), and the healing rates are over $90 \%$ [5]. In addition to sphincterotomy, fissurectomy is the first-line surgical therapy in many countries [6-8]. Despite its efficacy, complications have already been described after sphincterotomy, such as minor fecal incontinence, difficulty controlling flatulence, bleeding, peri-anal abscess formation and hematomas [9]. This issue in turn severely affects the quality of life [10], especially in young people. Another problem after surgical treatment is recurrence of the fissure, which can be seen approximately in $1-8 \%$ of the patients $[11,12]$ or non-healing of the fissure. By virtue of the patients' ability to choose their treatment, studies demonstrate that patients are willing to try less invasive modalities with the hope of avoiding surgery, with its risk of disability [13].

Sacral nerve stimulation (SNS) has recently been shown to be effective for the management of chronic anal fissure; however, it is an invasive technique [3]. Therefore, as a noninvasive alternative treatment, we aimed to stimulate similar nerves such as the posterior tibial nerve (PTN) by transcutaneous electrical nerve stimulation (TENS). The PTN comes from the sciatic nerve, and by stimulating this nerve in the ankle, it may mimic the effects of SNS and may improve chronic anal fissure. The technique PTN TENS has shown promising results for urinary incontinence [14] and fecal incontinence [15, 16].

\section{Materials and methods:-}

Twenty consecutive patients with the diagnosis of chronic anal fissure were enrolled in the study. Although there is no single universal definition of chronic anal fissure in the literature, chronicity of anal fissure is defined by most authors in terms of chronology (6-8 weeks) and presence of morphologic features such as visible transverse internal anal sphincter fibers, chronic granulation tissue at its base, or both and/or an indurated edge, a sentinel pile, and a hypertrophic anal papilla. In this study, we defined chronic anal fissure as persistence for more than 2 months and presence of at least one of the secondary features like papillae, piles, and indurated margins.

Full explanation was given to the patients who met the criteria for chronic anal fissure as defined above. All patients were aware of the noninvasive characteristic of the technique and that a standard validated treatment would be used in case of failure after the end of the procedure. Informed consent was obtained from each subject. Patients were included in the study if they were older than 18 years with chronic anal fissure for at least 2 months. Exclusion criteria were pregnancy, diabetes mellitus, neurological diseases, spinal cord lesions, and use of cardiac pacemaker or an implantable cardiac defibrillator. Prior to the procedure, the patients' medical history and clinical data were collected. The diagnosis of chronic anal fissure and the evaluation of anal fissure during the PTN TENS procedure were made by an expert colorectal surgeon. In all the patients, dietary modification had failed and they were treated with GTN cream and sitz baths at least for 1 month with no improvement in symptoms. This treatment was also further given during the procedure.

\section{TENS procedure}

TENS was applied with the use of a stimulating TENS unit CHATTANOOGA Group A Division of ENCORE Medical Fig1. Stimulation was applied on the PTN route with self-adhesive electrodes as described by Queralto et al. [15]. Contact electrodes were placed with electrode gel on the ankle skin with the negative electrode behind the medial malleolus and the positive electrode $10 \mathrm{~cm}$ above the negative electrode Fig2. The stimulation frequency was ap-plied at $10 \mathrm{~Hz}$ and at a pulse width of $200 \mathrm{~ms}$ in continuous mode. The correct position of the negative electrode was determined by visualization of rhythmic flexion of the toes secondary to plantar muscle contraction during stimulation delivered at $1 \mathrm{~Hz}$. The stimulus strength was below the motor threshold to produce a tingling sensation in the stimulated area without muscle twitch and pain which usually varied from 20 to $26 \mathrm{~mA}$. In every stimulation procedure, the patient increased the stimulus intensity by $1-\mathrm{mA}$ increments during the 20 -min period, every time until they get used to the tingling sensation of the current stimulus intensity. The maximum stimulus intensities recorded at the end of the stimulation procedure were between 26 and $38 \mathrm{~mA}$. The patients were invited to apply the procedure for 20 min every day for 5 days in a week, for a period of 2 weeks.

\section{Surgical assessment}

Wexner's constipation score [17] and visual analog scale (VAS) for pain were used for assessment of the severity of symptoms of chronic anal fissure at baseline and after the fifth and tenth sessions of TENS application. Symptom 
relief, compliance, and side effects of the procedure and the fissure healing were also documented in all patients after the fifth and tenth session and at follow-up.

Statistical analyses VAS for pain and Wexner's constipation scores were compared with repeated measures ANOVA. Chi-square test was used to evaluate the categoric variabilities. Ratio of symptom improvement was analyzed by Cochrane's $Q$ test. Change scores were determined by taking the difference of means between session 10 and session 1 . A p value of $<0.05$ was considered significant.

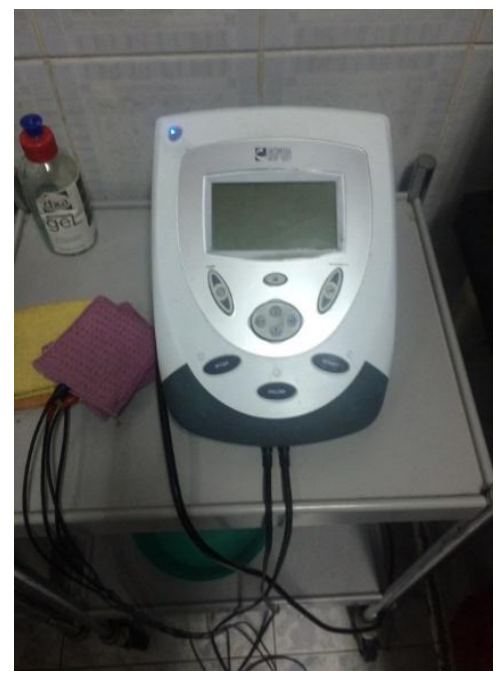

Figure 1

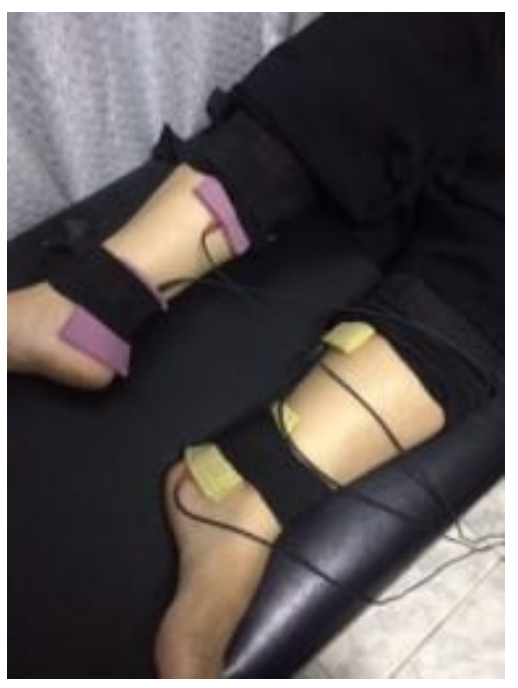

Figure 2

\section{Results:-}

TENS procedure was applied to twenty patients (fifteen women, five men) with a mean age of $34.75 \pm 11.42$ (range 19-55) years. The mean BMI was $26.15 \pm 2.83$ (range 21-30), and disease duration was $4.45 \pm 2.80$ (range 1-12) months.

All the patients completed the procedure by coming to the outpatient clinic for 30 days. The patients' demographic data, the symptoms, the localization, and the secondary features of the anal fissure and the medical history of the patients were shown in Table 1. The range of the stimulus intensity during TENS procedure and the improvement of the symptoms and fissure healing after the fifth and tenth sessions, 2nd TENS procedure and in the last follow-up were summarized in Table 2,3,4. The decrease in the ratio of symptoms and the healing of the fissure was 
statistically significant $(\mathrm{p}<0.029$ and $\mathrm{p}<0.048$, respectively).The VAS score at the beginning of procedure for all patients (twenty patients) was above 5, after the fifth session was above 5 for one patient, from 1-5 for sixteen patients and was 0 for three patients and after the tenth session VAS score was from 1-5 for four patients and 0 for sixteen patients.

The data of the VAS for pain and Wexner's constipation scores at the beginning and after the fifth and tenth Sessions were summarized in Table 5, 6.VAS score for pain decreased significantly from the fifth session to the tenth session. Wexner's constipation score also decreased significantly after the tenth session. There was a significant decrease in VAS for pain $(\mathrm{p}=0.000)$ and Wexner's constipation scores $(\mathrm{p}=0.000)$ with the TENS procedure. VAS score for pain decreased significantly after the fifth session $(\mathrm{p}=0.000)$. Wexner's constipation score also decreased significantly after the fifth session $(\mathrm{p}<0.000)$.

Treatment compliance was good in all cases, and all patients completed the study procedure. No significant side effects were seen. Pain and bleeding resolved in seventeen patients in the last follow up day after the treatment, and fissure healing which was defined as mucosal healing was observed in fifteen patients in the last follow up day after the treatment. All patients had secondary features such as sentinel piles, and all patients had indurated margins except one. Indurated margins resolved in all patients who showed mucosal healing though sentinel piles did not change with treatment. Fissure healing was seen in eight patients after the fifth session, in fourteen patients after the tenth session, and in fifteen patients at the last follow-up day. The six patients who had non-healing fissure at the end of the tenth session, the procedure was repeated again in two of them. The fissure healing was seen only in one of them after the second procedure in table 4.

In the follow-up, two out of five patients who had nonhealing fissure at the end of the last follow up day undergone lateral sphincterotomy after the TENS procedure due to persistence of symptoms (pain and constipation).

\section{Demographic data of the studied cases}

\begin{tabular}{|c|c|c|c|c|c|c|c|c|c|c|c|}
\hline \multirow[t]{2}{*}{ Patient } & \multirow[t]{2}{*}{ Gender } & \multirow[t]{2}{*}{ Age } & \multirow[t]{2}{*}{ BMI } & \multirow{2}{*}{$\begin{array}{c}\text { Disease } \\
\text { duration } \\
\text { (month) }\end{array}$} & \multicolumn{3}{|c|}{ Symptoms } & \multirow{2}{*}{$\begin{array}{c}\text { Fissure } \\
\text { Type }\end{array}$} & \multirow{2}{*}{$\begin{array}{l}\text { Fissure } \\
\text { location }\end{array}$} & \multirow{2}{*}{$\begin{array}{l}\text { Secondary } \\
\text { features }\end{array}$} & \multirow[t]{2}{*}{ Comorbidities } \\
\hline & & & & & Pain & Bleeding & Constipation & & & & \\
\hline 1 & $\mathbf{M}$ & 35 & 27 & 4 & + & + & _ & Primary & $\mathbf{P}$ & $\mathbf{S P}$ & Appendectomy \\
\hline 2 & $\mathbf{M}$ & 40 & 30 & 3 & + & + & - & Primary & $\mathbf{P}$ & SP & \\
\hline 3 & $\mathbf{M}$ & 52 & 29 & 5 & + & - & + & Primary & $\mathbf{P}$ & SP & Hemorrhoidectomy \\
\hline 4 & M & 55 & 27 & 3 & + & 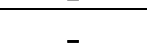 & + & Primary & $\mathbf{A}$ & SP & Asthma \\
\hline 5 & M & 24 & 22 & 6 & + & + & - & Recurrent & $\mathbf{P}$ & SP & LIS \\
\hline 6 & $\mathbf{F}$ & 30 & 28 & 2 & + & - & + & Primary & $\mathbf{A}+\mathbf{P}$ & SP & - \\
\hline 7 & $\mathbf{F}$ & 35 & 26 & 3 & + & - & + & Primary & $\mathbf{P}$ & SP & - \\
\hline 8 & $\mathbf{F}$ & 22 & 23 & 1 & + & + & - & Primary & $\mathbf{A}$ & SP & Cholecystectomy \\
\hline 9 & $\mathbf{F}$ & 32 & 27 & 4 & + & - & - & Primary & $\mathbf{P}$ & SP & - \\
\hline 10 & $\mathbf{F}$ & 38 & 21 & 7 & + & - & - & Primary & $\mathbf{P}$ & SP & - \\
\hline 11 & $\mathbf{F}$ & 19 & 22 & 1 & + & - & + & Primary & $\mathbf{A}$ & SP & - \\
\hline 12 & $\mathbf{F}$ & 41 & 28 & 4 & + & + & + & Primary & $\mathbf{P}$ & SP & Hemorrhoidectomy \\
\hline 13 & $\mathbf{F}$ & 45 & 29 & 5 & + & + & + & Primary & $\mathbf{P}$ & SP & Breast cancer \\
\hline 14 & $\mathbf{F}$ & 20 & 24 & 1 & + & - & - & Primary & $\mathbf{P}$ & SP & - \\
\hline 15 & $\mathbf{F}$ & 28 & 27 & 8 & + & 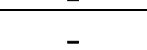 & + & Recurrent & $\mathbf{P}$ & SP & Cholecystectomy \\
\hline 16 & $\mathbf{F}$ & 27 & 26 & 12 & + & - & + & Primary & $\mathbf{A + P}$ & SP & - \\
\hline 17 & $\mathbf{F}$ & 55 & 30 & 6 & + & + & + & Primary & $\mathbf{P}$ & SP & Appendectomy \\
\hline 18 & $\mathbf{F}$ & 25 & 27 & 8 & + & - & - & Primary & $\mathbf{P}$ & SP & - \\
\hline 19 & $\mathbf{F}$ & 46 & 28 & 2 & + & _- & _- & Primary & $\mathbf{P}$ & SP & Hemorrhoidectomy \\
\hline 20 & $\mathbf{F}$ & 26 & 22 & 4 & + & + & _- & Primary & $\mathbf{A}$ & SP & - \\
\hline
\end{tabular}

Table 1:-F female, M male, BMI body mass index, A anterior, $\mathrm{P}$ posterior, LIS lateral internal sphincterotomy, SP sentinel 
Table 2:-Symptoms improvement among the studied cases

\begin{tabular}{|c|c|c|c|c|c|c|c|c|c|}
\hline \multirow{2}{*}{ Symptoms } & \multicolumn{2}{|c|}{ 5th day } & \multicolumn{2}{|c|}{ 10th day } & \multicolumn{2}{|c|}{ last FU day } & \multirow{2}{*}{ Test value* } & \multirow{2}{*}{ P-value } & \multirow{2}{*}{ Sig. } \\
\hline & No. & $\%$ & No. & $\%$ & No. & $\%$ & & & \\
\hline Negative & 10 & $50.0 \%$ & 16 & $80.0 \%$ & 17 & $85.0 \%$ & 7059 & 0029 & $\mathrm{~S}$ \\
\hline Positive & 10 & $50.0 \%$ & 4 & $20.0 \%$ & 3 & $15.0 \%$ & 1.059 & 0.029 & $\mathrm{~S}$ \\
\hline
\end{tabular}

P-value >0.05: Non-significant (NS); P-value <0.05: Significant (S); P-value< 0.01: Highly significant (HS)

*: Chi square test

Table 3:-Fissure healing among the studied cases

\begin{tabular}{|c|c|c|c|c|c|c|c|c|c|}
\hline \multirow{2}{*}{ Fissure healing } & \multicolumn{2}{|c|}{ 5th day } & \multicolumn{2}{|c|}{ 10th day } & \multicolumn{2}{c|}{ last FU day } & \multirow{2}{*}{ Test value } & \multirow{2}{*}{ P-value } & \multirow{2}{*}{ Sig. } \\
\cline { 2 - 8 } & No. & \% & No. & \% & No. & \% & & & \\
\hline No & 12 & $60.0 \%$ & 6 & $30.0 \%$ & 5 & $25.0 \%$ & \multirow{2}{*}{6.063} & 0.048 & S \\
\hline Yes & 8 & $40.0 \%$ & 14 & $70.0 \%$ & 15 & $75.0 \%$ & & \\
\hline
\end{tabular}

P-value >0.05: Non-significant (NS); P-value <0.05: Significant (S); P-value< 0.01: highly significant (HS)

*: Chi square test

Table 4:-2nd TENS procedure, follow up time, and TENS score among the studied cases

\begin{tabular}{|c|c|c|}
\hline \multicolumn{2}{|c|}{} & No. $\mathbf{2 0}$ \\
\hline \multirow{2}{*}{ 2nd TENS procedure } & Negative & $18(90.0 \%)$ \\
\cline { 2 - 3 } & Positive & $2(10.0 \%)$ \\
\hline \multirow{2}{*}{ Last FU time (months) } & Mean \pm SD & $4.45 \pm 1.64$ \\
\cline { 2 - 3 } & Range & $2-8$ \\
\hline \multirow{2}{*}{ TENS, mA (min-max) } & Mean \pm SD & $29.10 \pm 2.59$ \\
\cline { 2 - 3 } & Range & $24-34$ \\
\hline
\end{tabular}

Table 5:-VAS score at different times of measurement

\begin{tabular}{|c|c|c|c|c|c|c|}
\hline \multirow[t]{2}{*}{ VAS } & Baseline & 5th session & 10th session & \multirow[t]{2}{*}{ Test value } & \multirow[t]{2}{*}{ P-value } & \multirow[t]{2}{*}{ Sig. } \\
\hline & No. $=20$ & No. $=20$ & No. $=20$ & & & \\
\hline Median (IQR) & $8(7.5-9)$ & $1(1-5)$ & $0(0-0)$ & \multirow[t]{2}{*}{38.316} & \multirow[t]{2}{*}{0.000} & \multirow[t]{2}{*}{$\mathrm{HS}$} \\
\hline Range & $6-10$ & $0-8$ & $0-5$ & & & \\
\hline $\mathrm{VAS}=0$ & $0(0.0 \%)$ & $3(15.0 \%)$ & $16(80.0 \%)$ & \multirow[t]{3}{*}{79.928} & \multirow[t]{3}{*}{0.000} & \multirow[t]{3}{*}{$\mathrm{HS}$} \\
\hline VAS $1-5$ & $0(0.0 \%)$ & $16(80.0 \%)$ & $4(20.0 \%)$ & & & \\
\hline VAS > 5 & $20(100.0 \%)$ & $1(5.0 \%)$ & $0(0.0 \%)$ & & & \\
\hline
\end{tabular}

P-value >0.05: Non-significant (NS); P-value <0.05: Significant (S); P-value< 0.01: highly significant (HS)

f: Friedman test

Table 6:-Wexner's constipation score at different time of measurement

\begin{tabular}{|c|c|c|c|c|c|c|}
\hline \multirow{2}{*}{$\begin{array}{c}\text { Wexner's Constipation } \\
\text { Score System }\end{array}$} & Baseline & 5th session & 10th session & \multirow[t]{2}{*}{ Test value• } & \multirow[t]{2}{*}{ P-value } & \multirow[t]{2}{*}{ Sig. } \\
\hline & No. $=20$ & No. $=20$ & No. $=20$ & & & \\
\hline Mean \pm SD & $12.65 \pm 1.39$ & $8.85 \pm 3.13$ & $6.65 \pm 4.27$ & \multirow[t]{2}{*}{65.975} & \multirow[t]{2}{*}{0.000} & \multirow[t]{2}{*}{$\mathrm{HS}$} \\
\hline Range & $10-15$ & $5-14$ & $2-13$ & & & \\
\hline
\end{tabular}

P-value >0.05: Non-significant (NS); P-value <0.05: Significant (S); P-value< 0.01: highly significant (HS)

$\bullet:$ Repeated measure ANOVA test

\section{Discussion:-}

In this pilot study, we aimed to evaluate the effects of PTN TENS on chronic anal fissure symptoms and fissure healing. We demonstrated that PTN TENS had significantly improved symptoms in patients suffering from chronic anal fissure with a significant improvement in VAS for pain and Wexner's constipation score and with the healing of the fissure in fifteen out of twenty patients. The treatment of anal fissure is challenging. There are continued efforts to find a medical therapy or noninvasive intervention for anal fissure that is as successful as the surgical therapy. Sacral nerve stimulation has been recently shown to be effective in a study performed in five chronic anal fissure patients and in a case report by Yakovlev et al. [3] and Yakovlev and Karasev [18]. However, this technique leads to 
an invasive surgical procedure with a risk of related complications and the number of procedures is limited by the high cost of implanted stimulator [15]. PTN TENS is a possible alternative to SNS because the neurophysiologic targets might be similar. PTN arises from the ventral branches of the fourth and fifth lumbar and first second and third sacral nerves. As the nerve contains fibers from sacral nerves, stimulation of its peripheral fibers, which reach the ankle area, transmits impulses to the sacral nerves and causes reflex neuromodulation of the rectum and anal sphincter [15].

The mechanism of the analgesia produced by TENS is explained by the gate control theory proposed by Melzack and Wall in 1965 [19]. Although the gate control theory is the most widely accepted mechanism of TENS, other postulated mechanisms include inhibition of an abnormally excited nerve, restoration of afferent input, stimulation of endogenous opiate secretion in the brain, sympathetic block-age, and local dilatation of blood vessels in injured tissue [20-21]. The most prominent finding in anal fissures is spasm of the internal anal sphincter, which is so severe that the pain caused by fissure is thought to be due to ischemia [22]. Relief of the spasm has been associated with relief of pain and healing of the fissure.

The exact mechanism of action is not fully understood, however, there are many theories suggest that. The accurate stimulation parameters and the ideal response that needs to be elicited during stimulation are still unclear. We used the same stimulation parameters as first described by Queralto et al. [15]. According to some studies, both the presence of a motor and a sensory response is described as the ideal response to stimulation, while in other studies, the presence of either a motor or a sensory response alone is described as an ideal response [23, 24]. In our technique, we used a combined motor response (evidenced by the flexion of the big toe) and a sensory response (evidenced by a tingling sensation felt on the foot) as the stimulation parameters. However, further studies are needed to standardize the stimulation parameters for TENS proce-dure in anal fissure treatment. The results of our study do not offer any insight in the physiological mechanism of this technique. However, the beneficial effect of this technique on chronic anal fissure might be due to the parasympathetic activation leading to internal anal sphincter relaxation with positive effect on the spasm subsequently improving ischemia. Another mechanism of action of TENS might be the increase in rectal mucosal blood flow [25], leading to improvement in ischemia.

TENS procedure was also tolerated well, and no significant side effects were seen. Fissure healing was seen in eight patients after the fifth session and in fourteen patients after the tenth session and in fifteen patients after the last follow up day. In two out of the sixth patients who had a partial healing at the end of the tenth session, the procedure was repeated again. The fissure healing was seen only in one of them after the second procedure. This may suggest that a stable improvement rate might be seen with the chronic stimulation. It is still under debate whether the effect of TENS is maintained over a long period of time with the chronic stimulation. In a pediatric study with micturition disorders, performed by van der Pal, maintenance of treatment has been shown to be necessary to successfully treat patients with PTN stimulation [26]. However, a study performed by Nuhoglu et al. showed that only half of the patients treated for overactive bladder had a successful out-come after a 1-year follow-up [27]. There was not any recurrence in the fifteen patients with the fissure healing. This observation may suggest that PTN TENS therapy may have a long-term effect, which should be clarified with further studies. In two out of the fifth patients who had not fissure healing at the end of the last follow up day undergone lateral sphinctertomy because of non-healing fissure. Our study had methodological limitations including the lack of a control group, and the study was done by limited number of patients. Another limitation is the short follow-up time. Also, a placebo effect might have influenced our results. It has been shown that TENS had $32 \%$ placebo analgesic effect, but fissure healing seen in seven patients in this study suggests that it might have an effect more than this [28]. A double-blinded, crossover study of sacral neuromodulation by Vaizey and colleagues suggested that the observed effect is not due to a placebo effect [29]. However, placebo-controlled studies will be necessary to evaluate the efficacy of this technique. Finally, we had a female predominance in our study group with a high rate of anterior fissures, restricting the generalization of our results to both genders. Although the most common location for primary AF is the posterior anal midline, 10 $\%$ of females and $1 \%$ of males have a fissure located in the anterior midline [29, 30]. This might explain why anterior fissures were more frequent in our female patients, which might have had an impact on the outcome. In conclusion, the results of our study suggest that PTN TENS may be an effective method for the treatment of Chronic anal fissure with rapid relief of symptoms and fissure healing. It is a noninvasive treatment option, which can also be used possibly in a home setting. However, our findings should be verified in larger controlled series.

\section{Conflict of interest}

The authors have no conflict of interest to declare. 


\section{References:-}

1. Barton J (2002) Nitroglycerin and lidocaine topical treatment for anal fissure. RxTriad 5(4):1-2

2. Poh A, Tan KY, Choen FS (2010) Innovations in chronic anal fissure treatment: a systematic review. World J Gastrointest Surg 2(7):231-241

3. Yakovlev A, Karasev SA, Dolgich OY (2011) Sacral nerve stimulation: a novel treatment of chronic anal fissure. Dis Colon Rectum 54:324-327

4. Nelson RL, Thomas K, Morgan J, Jones A (2012) Non-surgical therapy for anal fissure. Cochrane Database Syst Rev 2:CD003431, Review. PubMed PMID:22336789

5. Nelson RL, Chattopadhyay A, BrooksW, Platt I, Paavana T, Earl S (2011) Operative procedures for fissure in ano. Cochrane Database Syst Rev 9(11):CD002199, Review. PubMed PMID: 22071803

6. Patti R, Territo V, Aiello P, Angelo GL, DiVita G (2012) Manometric evaluation of internal anal sphincter after fissurectomy and anoplasty for chronic anal fissure: a prospective study. Am Surg 78(5):523-527

7. Schornagel IL, Witvliet M, Engel AF (2012) Five-year results of fissurectomy for chronic anal fissure: low recurrence rate and minimal effect on continence. Colorectal Dis 14(8):997-1000

8. Abramowitz L, Bouchard D, Souffran M et al (2013) Sphincter sparing anal-fissure surgery: a 1-year prospective, observational, multicenter study of fissurectomy with anoplasty. Colorectal Dis 15(3):359-367

9. khubchandani IT, Reed JF (May 1989):

10. "Sequelae of internal sphincterotomy for chronic anal fissure in ano". Br J Surg. 76 (5): 431-4.

11. Casillas S, Hull TL, Zutshi M, Trzcinski R, Bast JF, Xu M (2005) Incontinence after a lateral internal sphincterotomy: are we underestimating it? Dis Colon Rectum 48(6):1193-1199

12. Renzi A, Izzo D, Di Sarno G et al (2008) Clinical, manometric, and ultrasonographic results of pneumatic balloon dilatation vs. lateral internal sphincterotomy for chronic anal fissure: a prospective, randomized, controlled trial. Dis Colon Rectum 51(1):121-127

13. Shao WJ, Li GC, Zhang ZK (2009) Systematic review and metaanalysis of randomized controlled trials comparing botulinum toxin injection with lateral internal sphincterotomy for chronic anal fissure. Int $\mathbf{J}$ Colorectal Dis 24(9):995-1000

14. Sinha R, Kaiser AM (2012) Efficacy of management algorithm for reducing need for sphincterotomy in chronic anal fissures. Colorectal Dis 14(6):760-764

15. Schreiner L, dos Santos TG, Knorst MR, da Silva Filho IG (2010) Randomized trial of transcutaneous tibial nerve stimulation to treat urge urinary incontinence in older women. Int Urogynecol J 21(9):1065-1070

16. Queralto M, Portier G, Cabarrot PH et al (2006) Preliminary results of peripheral transcutaneous neuromodulation in the treatment of idiopathic fecal incontinence. Int J Colorectal Dis 21:670-672

17. Veronique V, Henri D, Sabine R, Francois M (2010) Transcutaneous electrical posterior tibial nerve stimulation for faecal incontinence: effects on symptoms and quality of life. Int J Colorectal Dis 25:1017-1020

18. Agachan F, Chen T, Pfeifer J, Reissman P, Wexner SD (1996) A constipation scoring system to simplify evaluation and management of constipated patients. Dis Colon Rectum 39:681-685

19. Yakovlev A, Karasev SA (2010) Successful treatment of chronic anal fissure utilizing sacral nerve stimulation. Wisconsin Medical Journal 109(5):279-281

20. Melzack R, Wall PD (1965) Pain mechanisms: a new theory. Science 150:971-975

21. Kathleen A (2003) TENS basic science mechanisms and clinical effectiveness. J Pain 4:109-121

22. Papanicolaou GD, McCabe SJ, Firrell J (2001) The prevalence and characteristics of nerve compression symptoms in the general population. J Hand Surg Am 26:460-466

23. Schouten WR, Briel JW, Auwerda JJ (1994) Relationship between anal pressure and anodermal blood flow: the vascular pathogenesis of anal fissures. Dis Colon Rectum 37:664-669

24. George AT, Kalmar K, Sala S et al (2013) Randomized controlled trial of percutaneous versus transcutaneous posterior tibial nerve stimulation in faecal incontinence. Br J Surg 100:330-338

25. George AT, Vaizey CJ (2013) Percutaneous posterior tibial nerve stimulation for fecal incontinence: are we all reading from the same page? Dis Colon Rectum 56: e328-e329

26. Mentes BB, Yüksel O, Aydin A, Tezcaner T, Leventoglu A, Aytaç B (2007) Posterior tibial nerve stimulation for faecal incontinence after partial spinal injury: preliminary report. Tech Coloproctol 11:115-119

27. van der Pal F, van Balken MR, Heesakkers JP, Debruyne FM, Bemelmans BL (2006) Percutaneous tibial nerve stimulation in the treatment of refractory overactive bladder syndrome: is maintenance treatment necessary? BJU Int 97:547-550

28. Nuhoglu B, Fidan V, Ayyildis A, Ersoy E, Germiyanoglu C (2006) Stoller afferent nerve stimulation in woman with therapy resistant over active bladder; a 1-year follow-up. Int Urogynecol J17:204- 207

29. Thorsteinsson G, Stonnington HH, Stilwell GK et al (1978) The placebo effect of transcutaneous electrical 
stimulation. Pain 5:31-41

30. Vaizey CJ, Kamm MA, Roy AJ, Nicholls RJ (2004) Double-blind crossover study of sacral nerve stimulation for fecal incontinence. Dis Colon Rectum 43:298-302

31. Madalinski MH (2011) Identifying the best therapy for chronic anal fissure. World J Gastrointest Pharmacol Ther 2(2):9 16. 